\title{
Clinical and functional outcomes of pre-contoured plate fixation in displaced intraarticular calcaneum fracture
}

\author{
B. L. S. Kumar Babu1, Bhaskar Amarnath Bhavanasi², Narreddy Jayasomeswar Reddy ${ }^{3 *}$
}

\begin{abstract}
${ }^{1}$ Department of Orthopedics, Narayana Medical College, Nellore, Andhra Pradesh, India
${ }^{2}$ Department of Trauma \& Orthopedics, Sandwell and West Brimingham Trust, West Bomrwich, United Kingdom

${ }^{3}$ Department of Orthopedics, Narayana Medical College, Nellore, Andhra Pradesh, India
\end{abstract}

Received: 26 January 2020

Revised: 10 February 2020

Accepted: 11 February 2020

\author{
*Correspondence: \\ Dr. Narreddy Jayasomeswar Reddy, \\ E-mail: drpramamohan@narayanamedicalcollege.com
}

Copyright: (C) the author(s), publisher and licensee Medip Academy. This is an open-access article distributed under the terms of the Creative Commons Attribution Non-Commercial License, which permits unrestricted non-commercial use, distribution, and reproduction in any medium, provided the original work is properly cited.

\section{ABSTRACT}

Background: We evaluated the clinical and functional outcome of intra-articular calcaneal fractures treated with precontoured plating. The functional outcome was measured by the American Orthopaedic Foot and Ankle Society (AOFAS) scoring system.

Methods: Twenty-five adult patients with displaced intra-articular calcaneus fractures, treated with by open reduction and internal fixation using pre-contoured plates, and those who were available for follow up were evaluated for the outcomes such as operative procedure, anatomical reduction, postoperative hospital stays early mobilization and functional outcome postoperatively. Follow-up was at three, six and twelve months radiological and clinical union were also considered.

Results: Twenty-five adult patients presented with calcaneal fractures were operated during the study period. The mean time for union of fracture was $12.5 \pm 1.8$ weeks. When we assessed the functional outcome in those patients who had radiological and clinical union using AOFAS score, we found that 16 out of $23(64 \%)$ had good results with mean AOFAS score of $83.5 \pm 2.0$ and $7 / 25(28 \%)$ had fair results with mean score of $73.3 \pm 1.3$, and $2 / 25(8 \%)$ had poor results with mean score of $54.0 \pm 8.5$. In 2 out of $16(12.5 \%)$ patients, with good AOFAS scores, implants were removed after one and a half year from the day of surgery after confirming complete union of the fracture.

Conclusions: We believe that pre-contoured reconstruction plate fixation for displaced intraarticular calcaneus fracture is excellent in terms of the union of the fracture, attaining anatomical reduction. It gives better outcomes concerning the function and range of movements.

Keywords: Bohler's angles, Gissane's angles, Clinical union, AOFAS scores

\section{INTRODUCTION}

Fractures of calcaneum account for about 2 percentage of all fractures. Intraarticular forms are 70 to 75 percentage of all calcaneum fractures. The varying degrees of shear force at calcaneum with axial load is the root cause of these fractures. There is a controversy between surgeons about whether operative or non-operational calcaneum care provides better clinical outcomes and functional outcomes. ${ }^{1}$ Because of its unique shape, problems arose in understanding the structure and location of the calcaneal fractures, the complications of the surgical treatment were present until recently. Advanced imaging technology has allowed a better understanding of the anatomy of fractures and revolutionized the treatment of calcaneus fractures.

While the literature indicates significant benefit from surgical treatment of these fractures, in many studies, complications have been shown to be a common 
problem. Surgical treatment options include open reduction and internal fixation, percutaneous fixation and primary arthrodesis. ${ }^{2}$ There is no consensus on the surgical approach; however, with many of them being identified, including mixed medial, lateral, medial and lateral, lateral and sinus tarsi approaches extended. ${ }^{3}$

However, the stabilization methods remain a point of debate, with various advocates promoting fastening with k-wires, screws, or screw fastening plate. ${ }^{4}$ The purpose of this study is to test outcomes such as the use of lesser hardware and to provide better functional results in terms of shorter treatment time, improved stability and early weight-bearing of precontoured plate fixation in displaced intraarticular calcaneus fractures.

\section{METHODS}

This study was conducted during the period September 2016 to January 2019 at Narayana Medical College, Nellore, Andhra Pradesh. Institutional ethics committee approved the study proposal. Twenty-five adult patients with displaced intra-articular calcaneus fractures, treated with by open reduction and internal fixation using precontour plates, and those who were available for follow up were evaluated for the outcomes such as operative procedure, anatomical reduction, postoperative hospital stays, early mobilization and functional outcome postoperatively.

\section{Inclusion criteria}

All patients above 18 years of age with intra-articular calcaneum fractures, fresh fractures were included.

\section{Exclusion criteria}

Open fractures, pathological fractures, calcaneal fractures with other associated fracture in lower limb, fractures in children, fractures in adults $>55$ years, grossly comminuted fractures, severely osteoporotic bone were excluded.

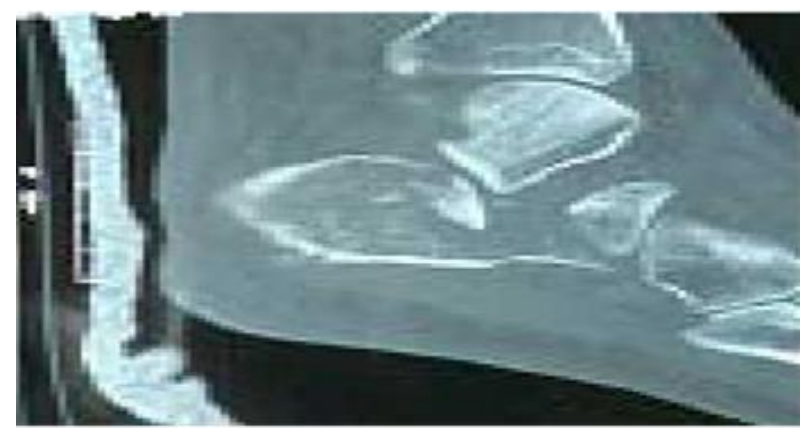

Figure 1: Pre-operative X-ray showing intra articular calcaneal fracture.

A thorough history and clinical examination were done. The swelling of the heel and status of the skin was recorded. Roentograms of the calcaneum were taken on admission, which included AP, lateral and axial views (Figure 1). CT scans were taken to evaluate the fracture pathology further. The patient was temporarily put on a below-knee slab with adequate limb elevation until the swelling subsided, and there were wrinkles seen on the lateral aspect of the heel. The fractures were classified based on the Essex-Lopresti and Sander's classification. The patient was then posted for open reduction internal fixation with precontoured reconstruction plates (Figure 2). The lateral extensile approach was used for all the patients. All the surgeries were conducted in the same centre by two orthopaedic surgeons who were all well trained in the procedure.

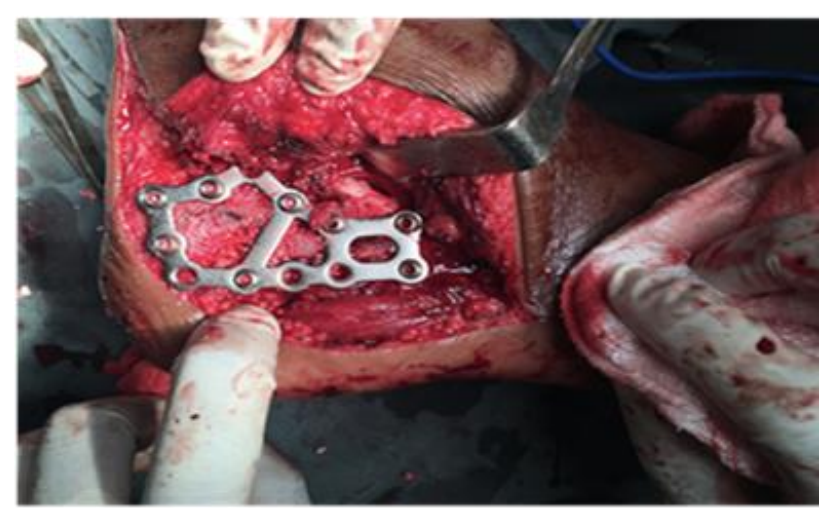

Figure 2: Per operative pre contoured plate fixation.

\section{Follow up and criteria for evaluation}

The patients were followed up clinically and radiologically at 6 weeks, 12 weeks, six months, and one year, concerning the height of calcaneum, the width of the calcaneum, range of movements at the subtalar joint, tubero-talar angles. At every follow-up, clinical examination was done to assess the status of the surgical wound, pain, tenderness, range of motion of the subtalar joint (Figure 4), stability of the fracture and clinical union. Roentgenograms were taken in lateral and axial views to look for signs of the radiological union (Figure 3).

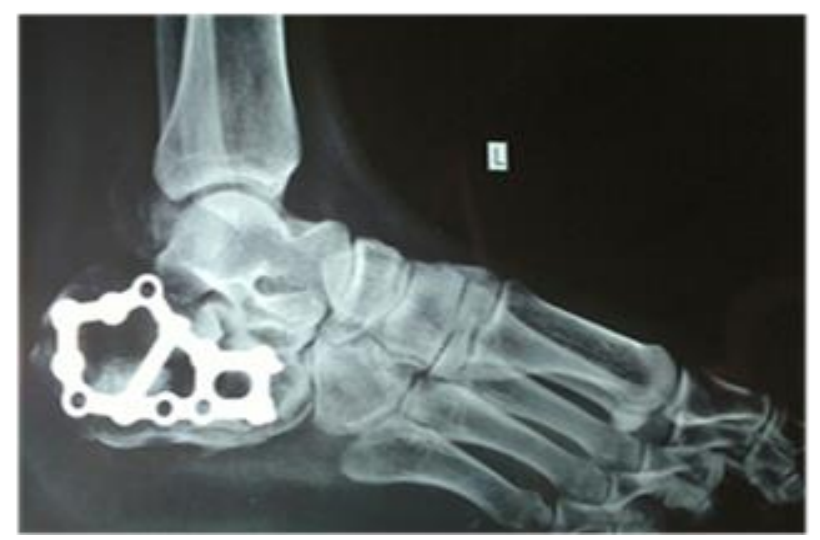

Figure 3: Post op X-ray showing pre contoured plate. 


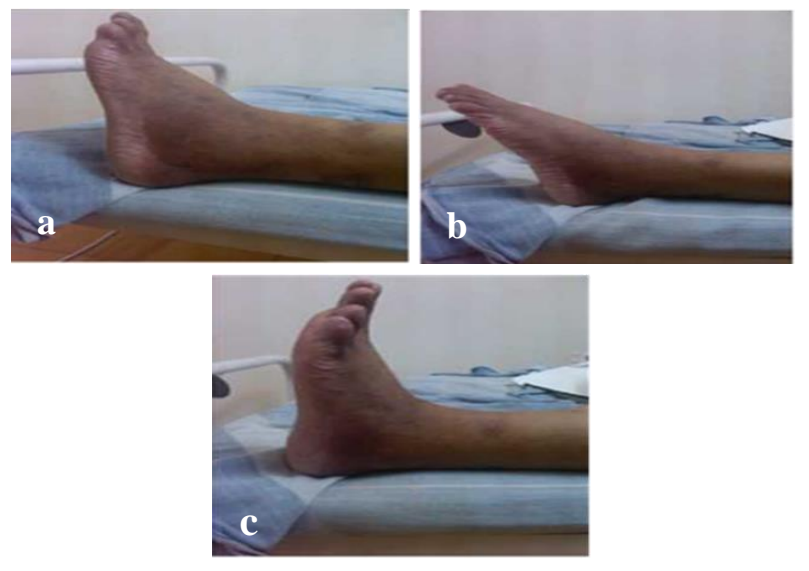

Figure 4 (A-C): Range of motion.

The clinical union was considered, when the fracture site had become stable and pain-free and radiologically union when the bone trabeculae or cortical bone crossing fracture site on at least three surfaces on orthogonal plain $\mathrm{X}$-rays. The time taken for the clinical and radiological union was noted. If there are no clinical and radiological signs of the union by 16 weeks, the fracture was categorized as delayed union and if the absence of fracture union after 24 weeks after injury was categorized as non-union.

The functional outcome was measured by the "American Orthopaedic Foot and Ankle Society (AOFAS) ankle hindfoot scoring system" at twelve months. The AOFAS scoring system is a handy tool to measure the function of the foot developed by the American Academy of Orthopaedic Surgeons and has been validated by various studies.58 The AOFAS score is a 100-point scoring system mainly assessing the pain, function and alignment of the foot. The functional outcome decreases as the score decreases. The result was then graded as excellent if the AOFAS was between (89 to 100 points), good (79 to 89 points), fair (69 to 79 points) and poor (less than 60 points).

\section{Statistical analysis}

Source data were recorded into Microsoft excel spreadsheet 2016 and them imported to IBM Corp. Released in 2016. IBM SPSS Statistics for Windows, Version 24.0. Armonk, NY: IBM Corp. Tables were generated using custom tables option. The relevant, measurements were reported as mean, standard deviation, actual numbers and percentages. Chi-square test and ANOVA were used appropriately for assessing group differences. When a two-tailed $\mathrm{p}$ value is less than 0.05 , the difference between groups was considered statistically significant.

\section{RESULTS}

Twenty-five adult patients presented with calcaneal fractures were operated at our hospital during the study period. All were males; the age group of these patients was between 19 to 56 years $(36.9 \pm 9.2$ years). The mode of injury in all the patients was fall from height. Gross swelling of the foot following the fall was observed in all the patients, only 5 out of $25(20 \%)$ had blisters associated with it. All the categorical results were tabulated in Table 1 and results of continuous variables in Table 2.

Table 1: Relationship between functional outcome grading with demographic and clinical variables measured on category scale in patients undergoing contoured plate fixation in displaced intraarticular calcaneum fracture.

\begin{tabular}{|c|c|c|c|c|c|c|c|c|c|}
\hline \multirow[t]{2}{*}{ AOFAS score } & \multirow{2}{*}{$\begin{array}{l}\text { Category } \\
\text { variables }\end{array}$} & \multicolumn{2}{|c|}{$\begin{array}{l}\text { Good } \\
(n=16 / 23,64 \%)\end{array}$} & \multicolumn{2}{|c|}{$\begin{array}{l}\text { Fair } \\
(n=7 / 25,28 \%)\end{array}$} & \multicolumn{2}{|c|}{$\begin{array}{l}\text { Poor } \\
(n=2 / 25,8 \%)\end{array}$} & \multicolumn{2}{|c|}{$\begin{array}{l}\text { All patients } \\
(n=25 / 25,100 \%)\end{array}$} \\
\hline & & $\mathbf{N}$ & $\%$ & $\mathbf{N}$ & $\%$ & $\mathbf{N}$ & $\%$ & $\mathbf{N}$ & $\%$ \\
\hline \multirow{2}{*}{ Gender } & Males & 16 & 100 & 7 & 100 & 2 & 100 & 25 & 100 \\
\hline & Female & 0 & 0 & 0 & 0 & 0 & 0 & 0 & 0 \\
\hline \multirow{2}{*}{ Laterality } & Left & 11 & 69 & 3 & 43 & 2 & 100 & 16 & 64 \\
\hline & Right & 5 & 31 & 4 & 57 & 0 & 0 & 9 & 36 \\
\hline \multirow{2}{*}{ Sanders type } & II & 8 & 50 & 0 & 0 & 0 & 0 & 8 & 32 \\
\hline & III & 8 & 50 & 7 & 100 & 2 & 100 & 17 & 68 \\
\hline Swelling & Yes & 16 & 100 & 7 & 100 & 2 & 100 & 25 & 100 \\
\hline \multirow{2}{*}{ Blister } & No & 14 & 88 & 6 & 86 & 0 & 0 & 20 & 80 \\
\hline & Yes & 2 & 13 & 1 & 14 & 2 & 100 & 5 & 20 \\
\hline \multirow{4}{*}{$\begin{array}{l}\text { Subtalar } \\
\text { inversion } \\
\text { degrees }\end{array}$} & $0-10$ & 0 & 0 & 0 & 0 & 2 & 100 & 2 & 8 \\
\hline & $0-15$ & 0 & 0 & 5 & 71 & 0 & 0 & 5 & 20 \\
\hline & $0-20$ & 11 & 69 & 2 & 29 & 0 & 0 & 13 & 52 \\
\hline & $0-25$ & 5 & 31 & 0 & 0 & 0 & 0 & 5 & 20 \\
\hline \multirow{4}{*}{$\begin{array}{l}\text { Subtalar } \\
\text { eversion } \\
\text { degrees }\end{array}$} & $0-5$ & 0 & 0 & 0 & 0 & 1 & 50 & 1 & 4 \\
\hline & $0-10$ & 0 & 0 & 3 & 43 & 1 & 50 & 4 & 16 \\
\hline & $0-15$ & 6 & 38 & 4 & 57 & 0 & 0 & 10 & 40 \\
\hline & $0-20$ & 10 & 63 & 0 & 0 & 0 & 0 & 10 & 40 \\
\hline
\end{tabular}




\begin{tabular}{|c|c|c|c|c|c|c|c|c|c|}
\hline \multirow[t]{2}{*}{ AOFAS score } & \multirow{2}{*}{$\begin{array}{l}\text { Category } \\
\text { variables }\end{array}$} & \multicolumn{2}{|c|}{$\begin{array}{l}\text { Good } \\
(n=16 / 23,64 \%)\end{array}$} & \multicolumn{2}{|c|}{$\begin{array}{l}\text { Fair } \\
(\mathrm{n}=7 / 25,28 \%)\end{array}$} & \multicolumn{2}{|c|}{$\begin{array}{l}\text { Poor } \\
(n=2 / 25,8 \%)\end{array}$} & \multicolumn{2}{|c|}{$\begin{array}{l}\text { All patients } \\
(\mathrm{n}=\mathbf{2 5 / 2 5}, \mathbf{1 0 0 \%}\end{array}$} \\
\hline & & $\mathbf{N}$ & $\%$ & $\mathbf{N}$ & $\%$ & $\mathbf{N}$ & $\%$ & $\mathbf{N}$ & $\%$ \\
\hline \multirow{3}{*}{$\begin{array}{l}\text { Ankle } \\
\text { dorsiflexion } \\
\text { degrees }\end{array}$} & $0-15$ & 0 & 0 & 0 & 0 & 2 & 100 & 2 & 8 \\
\hline & $0-20$ & 0 & 0 & 7 & 100 & 0 & 0 & 7 & 28 \\
\hline & $0-30$ & 16 & 100 & 0 & 0 & 0 & 0 & 16 & 64 \\
\hline \multirow{2}{*}{$\begin{array}{l}\text { Ankle } \\
\text { plantarflexion } \\
\text { degrees }\end{array}$} & $0-15$ & 0 & 0 & 7 & 100 & 2 & 100 & 9 & 36 \\
\hline & $0-25$ & 16 & 100 & 0 & 0 & 0 & 0 & 16 & 64 \\
\hline \multirow{2}{*}{$\begin{array}{l}\text { Post-operative } \\
\text { pain }\end{array}$} & No & 12 & 75 & 5 & 71 & 0 & 0 & 17 & 68 \\
\hline & Yes & 4 & 25 & 2 & 29 & 2 & 100 & 8 & 32 \\
\hline \multirow{2}{*}{ Union } & Delayed & 0 & 0 & 1 & 14 & 2 & 100 & 3 & 12 \\
\hline & Normal & 16 & 100 & 6 & 86 & 0 & 0 & 22 & 88 \\
\hline
\end{tabular}

Table 2: Association of functional outcome grading with demographic and clinical variables measured on continuous scale in patients undergoing contoured plate fixation in displaced intraarticular calcaneum fracture.

\begin{tabular}{|c|c|c|c|c|c|}
\hline AOFAS & $\begin{array}{l}\text { Good } \\
(n=16 / 23,64 \%)\end{array}$ & $\begin{array}{l}\text { Fair } \\
(\mathrm{n}=7 / 25,28 \%)\end{array}$ & $\begin{array}{l}\text { Poor } \\
(n=2 / 25,8 \%)\end{array}$ & $P$ value & $\begin{array}{l}\text { All } \\
\text { patients }\end{array}$ \\
\hline Age (in years) & $37.6 \pm 9.1$ & $36 \pm 11.2$ & $35 \pm 4.2$ & $>0.05$ & $36.9 \pm 9.2$ \\
\hline $\begin{array}{l}\text { Time to surgery from } \\
\text { admission (days) }\end{array}$ & $5.6 \pm 2.0$ & $5.3 \pm 1.2$ & $14 \pm 0$ & $<0.05$ & $6.3 \pm 2.9$ \\
\hline $\begin{array}{l}\text { Duration of post-operative } \\
\text { stay (days) }\end{array}$ & $15.5 \pm 1.4$ & $15.5 \pm 1$ & $21 \pm 1.4$ & $<0.05$ & $16 \pm 2$ \\
\hline Time to union (weeks) & $12 \pm 0$ & $12 \pm 0$ & $18 \pm 2.8$ & $<0.05$ & $12.5 \pm 1.8$ \\
\hline $\begin{array}{l}\text { Pre op Bohler's angle } \\
\text { (degrees) }\end{array}$ & $12.9 \pm 3.3$ & $9.3 \pm 1.2$ & $7.5 \pm 0.7$ & $<0.05$ & $11.6 \pm 3.4$ \\
\hline $\begin{array}{l}\text { Post op Bohler's angle } \\
\text { (degrees) }\end{array}$ & $27.5 \pm 1.9$ & $24.9 \pm 2.9$ & $20 \pm 0$ & $<0.05$ & $26.2 \pm 3$ \\
\hline $\begin{array}{l}\text { Pre op Gissane's angle } \\
\text { (degrees) }\end{array}$ & $126.1 \pm 2.1$ & $127.8 \pm 3.2$ & $130 \pm 0$ & $>0.05$ & $126.9 \pm 2.6$ \\
\hline $\begin{array}{l}\text { Post op Gissane's angle } \\
\text { (degrees) }\end{array}$ & $118.8 \pm 1.2$ & $120.3 \pm 0.8$ & $126 \pm 1.4$ & $<0.05$ & $119.8 \pm 2.3$ \\
\hline Pre-op heel height (cm) & $6.1 \pm 0.2$ & $5.7 \pm 0.4$ & $5.4 \pm 0.5$ & $<0.05$ & $5.9 \pm 0.4$ \\
\hline Post-op heel height (cm) & $6.6 \pm 0.1$ & $6.2 \pm 0.4$ & $5.7 \pm 0.5$ & $<0.05$ & $6.4 \pm 0.4$ \\
\hline Pre-op heel width (cm) & $6.7 \pm 0.3$ & $7 \pm 0.3$ & $6.9 \pm 0.2$ & $>0.05$ & $6.8 \pm 0.3$ \\
\hline Post-op heel width (cm) & $6.1 \pm 0.2$ & $6.5 \pm 0.4$ & $6.7 \pm 0.2$ & $<0.05$ & $6.3 \pm 0.4$ \\
\hline AOFAS score & $83.5 \pm 2.0$ & $73.3 \pm 1.3$ & $54.0 \pm 8.5$ & $<0.05$ & $78.3 \pm 9.0$ \\
\hline
\end{tabular}

Among these patients, 16 out of 25 (64\%) had left-sided fractures, while 9 out of $25(36 \%)$ had right-sided fractures. Two patients had bilateral fractures (operated only on one side). All the operated patients had a joint depression type of fracture. 17 out of $25(68 \%)$ had Sander's type III fracture, and 8 out of $25(32 \%)$ had Sander's type II fracture. The number of days from the fall to surgery varied from 2 to 14 days (6.3 \pm 2.9 days). Duration of postoperative hospital stays varied from 14 to 22 days (16 \pm 2 days). The mean time for union of fracture was $12.5 \pm 1.8$ weeks.

All patients were operated with a lateral extensile approach and fixed with contoured recon plates. Postoperatively all 25 out of 25 (100\%) had swelling, 8 out of $25(32 \%)$ patients had persisting pain, 2 out of 25
(8\%) had superficial infections, and 1 out of $25(4 \%)$ had a deep infection. Patients with superficial infections were treated with injectable antibiotics for a week, and oral antibiotics for another week. Suture removal was delayed till the wound infection subsided, and patients were discharged. One patient with deep infection was treated repeatedly with a course of injectable and oral antibiotics. This patient had persistent pain and difficulty in walking with discharge from the surgical wound site at every follow up. X-ray showed delayed union. The patient developed calcaneal osteomyelitis and underwent implant removal and debridement after a year.

At 12 weeks of follow up, X rays of 23 out of 25 (92\%) patients showed radiological signs of the union. 2 out of $25(8 \%)$ patients had delayed union radiologically. One 
patient underwent implant removal at five months due to a screw-in subtalar joint while the other patient underwent implant removal at the end of 1 year due to deep infection.

In majority ROM of subtalar and ankle joints of patients with excellent results are as follows. Inversion and eversion are 0 to 20 degrees and 0 to 20 degrees respectively, and dorsiflexion and plantarflexion of ankle are 0 to 30 degrees and $0-25$ degrees respectively. In patients who were having fair results, the majority ROM of subtalar and ankle joints as follows. Inversion and eversion are 0-15 degrees and 0 to 10 degrees respectively, and dorsiflexion and plantarflexion of ankle are 0 to 20 degrees and $0-15$ degrees respectively. The ROM of subtalar and ankle joints of patients with poor results are as follows. Inversion and eversion are $<10$ degrees each, and the dorsiflexion and plantarflexion of ankle are 0 to 15 degrees each.

All the operated patients had an increase in the Bohler's angle and decrease in the Gissane's angle with a statistically significant. The mean pre-op Bohler's angle was increased from $11.6 \pm 3.4$ to $26.2 \pm 3$ degrees $(p<0.05$ ), while Gissane's angle was decreased from $126.9 \pm 2.6$ to $119.8 \pm 2.3$ degrees $(\mathrm{p}<0.05)$. Similarly, we also noticed that there was an increase in heel height and decrease in heel width, which were statistically significant $(\mathrm{p}<0.05)$. The heel height was increased $5.9 \pm 0.4 \mathrm{~cm}$ to $6.4 \pm 0.4 \mathrm{~cm}$, while heel width was decreased from $6.8 \pm 0.3$ to $6.3 \pm 0.4$ $\mathrm{cm}$.

When we assessed the functional outcome in those patients who had radiological and clinical union using AOFAS score, we found that 16 out of $23(64 \%)$ had good results with mean AOFAS score of $83.5 \pm 2.0$ and 7 out of $25(28 \%)$ had fair results with mean score of $73.3 \pm 1.3$, and 2 out of $25(8 \%)$ had poor results with mean score of $54.0 \pm 8.5$. In 2 out of $16(12.5 \%)$ patients, with good AOFAS scores, implants were removed after one and a half year from the day of surgery after confirming complete union of the fracture. Postoperatively these patients had no complaints.

\section{DISCUSSION}

The calcaneum is the most fractured tarsal bone. The management of every aspect of intra-articular calcaneal fractures is controversial. Although some studies have shown excellent results after open reduction and internal fixation of intraarticular calcaneal fractures, there is still debate over the best treatment option. ${ }^{5-8}$ Comparing findings between these studies is difficult, as different outcome measures are used, and there is no agreement among surgeons as to which is the most reliable and realistic method.

In our study, we have used the commonly used EssexLopresti and Sander's fracture classification systems. Although classifications show a positive correlation with the outcome, there is no correlation with the choice of treatment. $^{9-11}$ However, We believe that displaced calcaneum intraarticular fractures should be treated on the same principles as any other weight-bearing joint injury; that is, by anatomical reduction and rigid internal fixation, to allow early mobility and to create a better functional outcome. ${ }^{12}$

Calcaneal fracture surgery can be performed using medial, lateral or combined approaches. ${ }^{13}$ The lateral approach is the most popular approach. A lateral extensile exposure popularized by Benirschke and Sangeorzan was used in all our cases. We used a reconstruction plate contoured to the lateral wall of the calcaneum and screws to fix these fractures. The contoured plate was fixed, extending from the anterior process into the most posterior aspect of the tuberosity. When present, the "blow out" of the lateral wall could be well reduced and with this plate held in place.

In this study, we found an increase in the angle of Bohler and a decrease in the angle of Gissane. The alterations in these angles were correlated with the best patient satisfaction with their functional outcome. ${ }^{14}$

Ankle hindfoot scale is a standard foot function evaluation scoring system which accounts for patient subjective and objective assessments. It lets us get specific outcomes and compare them across studies. Melcher et al analyzed subjective and objective outcomes up to 10 years in their analysis and found better results than those obtained in a 3-year follow-up. ${ }^{15}$ In our study, $79 \%$ of patients had good, and $21 \%$ had fair or poor results, despite anatomic calcaneal restoration (as measured by the Bohler and Gissane angles) our study results were in line with Thodarsan et al and Sanders et al findings. ${ }^{6,7}$

Complications occur regardless of the management strategy chosen for intra-articular displaced fractures and despite management by experienced surgeons. The rate of wound complications (superficial and deep infections) in this study was similar to studies found in the literature. In our study, one patient developed a deep wound infection, which required implant removal. At the end of a one-year follow-up, his functional score was 48 . He will probably require subtalar joint fusion sometime in the future.

\section{CONCLUSION}

We agree that the intraarticular calcaneal fractures should be clinically treated with rigid pre-contoural reconstruction internal plate fixation to allow early movement and weight bearing. This improvement is associated with improvements in Bohler and Gissane's angle allowing better functional outcome and range of movements. A study involving more patients who have been followed up for a longer period of time can more accurately measure the functional outcome of displaced 
intraarticular calcaneal fractures that are treated with this procedure.

Funding: No funding sources

Conflict of interest: None declared

Ethical approval: The study was approved by the institutional ethics committee

\section{REFERENCES}

1. Ågren PH, Wretenberg P, Sayed-Noor AS. Operative Versus Nonoperative Treatment of Displaced Intra-Articular Calcaneal Fractures: A Prospective, Randomized, Controlled Multicenter Trial. JBJS. 2013;95(15):1351-7.

2. Nagamuneendrudu K. Fracture Calcaneum, Open Reduction and Internal Fixation: A Prospective Study. J Chalmeda Anand Rao Institute Med Sci. 2013;6(1):16.

3. Yeo JH, Cho HJ, Lee KB. Comparison of two surgical approaches for displaced intra-articular calcaneal fractures: sinus tarsi versus extensile lateral approach. BMC Musculoskelet Dis. 2015;16:63.

4. Lakhey S, Manandhar R, Pradhan R, Pandey B, Sharma S, Rijal K. Functional outcome of operatively treated displaced intra-articular calcaneal fractures using two parallel contoured reconstruction plates. Kathmandu Univ Med J. 2010;8(1):12-7.

5. Besse J-L, Avaro J-P, Chotel F, Lerat J-L, Moyen B. Calcaneal intra-articular fracture osteosynthesis: Clinical and radiological prospective study of 31 cases. Foot Ankle Surg. 2006;12(1):19-27.

6. Jain V, Kumar R, Mandal D. Osteosynthesis for Intra-Articular Calcaneal Fractures. J Orthop Surg. 2007;15(2):144-8.
7. Thordarson DB, Krieger LE. Operative vs. nonoperative treatment of intra-articular fractures of the calcaneus: a prospective randomized trial. Foot Ankle Int. 1996;17(1):2-9.

8. Buckley R. Operative care did not benefit closed, displaced, intra-articular calcaneal fractures. JBJS. 2015;97(4):341.

9. Bhattacharya R, Vassan U, Finn P, Port A. Sanders classification of fractures of the os calcis: an analysis of inter-and intra-observer variability. J Bone Joint Surg Br. 2005;87(2):205-8.

10. Humphrey CA, Dirschl DR, Ellis TJ. Interobserver reliability of a CT-based fracture classification system. J Orthop Trauma. 2005;19(9):616-22.

11. Schepers T, van Lieshout EM, Ginai AZ, Mulder PG, Heetveld MJ, Patka P. Calcaneal fracture classification: a comparative study. J Foot Ankle Surg. 2009;48(2):156-62.

12. Barei DP, Bellabarba C, Sangeorzan BJ, Benirschke SK. Fractures of the calcaneus. Orthop Clin. 2002;33(1):263-85.

13. Rak V, Ira D, Masek M. Operative treatment of intra-articular calcaneal fractures with calcaneal plates and its complications. Indian $\mathbf{J}$ Orthop. 2009;43(3):271.

14. Hart A, Eastwood D. Displaced intra-articular fractures of the calcaneum: what is new? Trauma. 2003;5(1):9-21.

15. Melcher G, Degonda F, Leutenegger A, Ruedi T. Ten-year follow-up after operative treatment for intraarticular fractures of the calcaneus. J Trauma Acute Care Surg. 1995;38(5):713-6.

Cite this article as: Babu BLSK, Bhavanasi BA, Reddy NJ. Clinical and functional outcomes of precontoured plate fixation in displaced intraarticular calcaneum fracture. Int J Res Orthop 2020;6:260-5. 